\title{
The Motivation of Football Players: The Impact of Coach Leadership Style in Malaysian Sports Schools
}

\author{
Mohamad Nasrullah Nasiruddin ${ }^{1,2^{*}}$, Mohd Sofian Omar Fauzee ${ }^{1}$, Ishak Sin ${ }^{1}$, Mohd Norakmar Omar ${ }^{1,2}$ \\ ${ }^{1}$ School of Education and Modern Languages, Universiti Utara Malaysia, Malaysia \\ ${ }^{2}$ Scholarship and Finance Division, Ministry of Education (Malaysia), Malaysia
}

Received July 2, 2020; Revised August 1, 2020; Accepted August 28, 2020

\begin{abstract}
Cite This Paper in the following Citation Styles
(a): [1] Mohamad Nasrullah Nasiruddin, Mohd Sofian Omar Fauzee, Ishak Sin, Mohd Norakmar Omar, "The Motivation of Football Players: The Impact of Coach Leadership Style in Malaysian Sports Schools," International Journal of Human Movement and Sports Sciences, Vol. 8, No. 4, pp. 124 - 133, 2020. DOI: 10.13189/saj.2020.080404.
\end{abstract}

(b): Mohamad Nasrullah Nasiruddin, Mohd Sofian Omar Fauzee, Ishak Sin, Mohd Norakmar Omar (2020). The Motivation of Football Players: The Impact of Coach Leadership Style in Malaysian Sports Schools. International Journal of Human Movement and Sports Sciences, 8(4), 124 - 133. DOI: 10.13189/saj.2020.080404.

Copyright $\odot 2020$ by authors, all rights reserved. Authors agree that this article remains permanently open access under the terms of the Creative Commons Attribution License 4.0 International License

\begin{abstract}
Malaysia is a country that has taken a severe approach to improving the quality and performance of the football team. To match the strength of the world-class football team, Malaysia has made a strategic approach by developing players' potential through the grassroots level. These players are brought together in sports schools across the country and raised by experienced coaches to showcase their talents, potentials, skills and performance in their style. Therefore, this study will identify the relationship between coach leadership style and the motivation of players in sports schools. Besides, the study also explored the dimensions of coach leadership style that have a high impact on improving player motivation. In this regard, a total of 313 footballers participating in the under-14 football tournament organized by MOEs from sports schools across Malaysia surveyed as respondents. The findings show that there is a moderate positive relationship between coach leadership style and players' motivation. Meanwhile, dimensions such as democratic and social consideration have a significant impact on increasing players' motivation in sports schools. In conclusion, the football coach is the most crucial person in ensuring the motivation of the players at a high level. They have to use all of their existing skills to build a strong, motivated team and never tire of it when facing tough moments in the game.
\end{abstract}

Keywords Football, Sports School, Players' Motivation, Coach Leadership Style, Youth

\section{Introduction}

Football is one of the most popular sports of all societies, regardless of gender, age or educational background. It is a sport that has a great aura in creating unity among all races and communities. Internationally, football teams from South American and European countries such as Brazil, Argentina, Uruguay, France, England, Spain and Italy are a favorite among football fanatic fans, and their players are revered and idolized. Not to be overlooked is the Belgian football team that is now showing consistency and winning the top rating of the Federation Internationale de Football Association (FIFA) in recent years [1].

In many countries, the quality of the football team is improving over time. National football teams such as Japan, South Korea, China, Saudi Arabia and Iran are the major footballing forces in Asia to qualify for the World Cup contests once every four years [2]. The quality of their games is far superior to the quality offered by other Asian teams. This situation has been a concern for most other Asian football teams as the chances of qualifying for the World Cup are increasingly difficult [3]. It is even more alarming when Australia's presence in the Asia Football Confederation (AFC) further complicates the dream of a dwarf football team to set foot on the world's leading football field.

As a developing country in Asian football, Malaysia is aware that higher level competition gives them a great opportunity further to enhance their players' performance 
and overall team quality. Therefore, the Football Association of Malaysia (FAM) is hoping for a higher competition organized by Malaysia to give them a chance to compete against the top teams in Asia. Among them are hosting the Asian Games in 2030, which will enable Malaysian football teams to compete automatically in the tournament [4].

Of course, the most important thing to remember in the last ten years is the process of football development from an early age. The method of finding talent among first childhood students is the most effective way of uncovering and shaping personalities, especially in physical, psychological, mental, decision making and tactical development [5]. These groups should be brought together and given the full attention of the government by providing a wide range of facilities, initiatives, welfare and infrastructure training centers [6]. Therefore, the action taken by the Malaysian government is to place potential football students in sports schools around the country.

\subsection{Problem Statements}

Football in Malaysia in recent times has experienced a slightly declined performance. According to FIFA (2020), Malaysia is ranked 167th out of 211 countries in the FIFA men's soccer rankings. The data in March 2020 is very different from Malaysia's success on the international stage for the past 20 years. For the record, Malaysia had previously ranked 75th in the FIFA rankings in August 1995 [7]. In comparison, it turns out that it is a conflict of interest why Malaysia's football performance has dropped so bad that Malaysia has achieved such glory.

Several studies have found that the decline of Malaysian football is due to a lack of motivation among players [8],[9]. Most players suffer from performance loss due to lack of motivation during the football match. This situation is particularly worrying as it continues from the senior squad to the junior team. It is known that the national youth squad is among the school-aged between 13 and 19 years old. If factors such as motivation are not emphasized earlier, these young players will likely follow the footsteps of senior players as they advance into the professional world [10].

Today, a group of junior college football players have gathered and are on-site at sports schools to pursue a more systematic intensive program. These players trained with a wide range of skills by experienced coaches, and most are former professional footballers and qualified teachers in the field of Sports Science [11]. The question is, can these coaches improve the motivation of the football players at the school? This situation is questionable because the learning environment at the sports school is not the same as it is at the regular school. Apart from studying, they also need to focus on football [12].

Several previous studies have shown that coach leadership style can enhance the well-being, motivation, interest and satisfaction of football among students $[12],[13],[14],[15]$. However, the approach adopted by the study is very different as it involves respondents of different ages, study locations and methods of coaching techniques practiced [9]. Given that Malaysia has a very unsettling history of football fall, it is appropriate that a study should be conducted to examine the motivation level of junior players in the 2020s. Also, it is essential to look at the influence played by existing coaches to motivate players for the sake of football in Malaysia.

\subsection{Research Objectives}

The objectives of this study are as follows:

(a) To determine the level of coach leadership style and players' motivation,

(b) To determine the differences in players' motivation based on demographic factors (types of school and playing experience),

(c) To identify the relationship coach leadership style and players' motivation,

(d) To identify the effect of coach leadership style on players' motivation.

\section{Literature Review}

\subsection{Coach Leadership Style}

A great football team starts with the role that a coach plays in providing coaching to every player. As such, aspects of coach leadership are fundamental and need to give an earnest emphasis on shaping the effectiveness of a credible coach that leads to success of the team [16]. The behaviours played by a coach has a profound effect on both the athlete and the team. If the coach can adapt, have high expectations and be liked by each player, then he can be a leader who can realize the goals and dreams of a team [13],[14].

Therefore, [16] has introduced a model called the multidimensional leadership model in which each coach must have three aspects of style: the style of leadership needed, the form of the leader and the style of the leader. All these three behaviours reflect the fact that when this style of leadership exists, the satisfaction, interest, and performance of the players will increase. Characteristics such as the personality, skills, experience and skills of the coaches are an asset for them to guide the players to a higher level [5],[16].

Earlier studies [17] described athletes being more comfortable and favoring a coach's behaviours if social relations between them were close. Studies involving rugby athletes also found that athletes' satisfaction and performance improved as coaches always encouraged and understood the problems they faced. Besides, reviews 
form [18] also agree that coaches who build good relationships with players will be their idols while also influencing high motivation. In the study, the average volleyball players decided that the coach's communication, instruction and actions were significant to the rise of their motivation in the game.

Given the importance of a coach's role in a team [19] found that there are six elements that a coach should possess. These elements developed in light of the demands put forth by [16] where coaches need to have their aura in shaping the players and teams they lead to excel in the future. The six elements of the coach's leadership style are as follows:

(a) Democratic: Coach's focus is on training, team spirit and a strong focus on the game's strategy. Usually, coaches who practice democratic style will try to get the players' views, discussion and consensus in making any decisions.

(b) Positive Feedback: It is a favorite of every player because this style of leadership will give recognition and reward to the players who perform well. Attitudes such as praise, encouragement and incentives are the most commonly used methods of a positive personality.

(c) Training and Instruction: Trainers who practice this style of leadership prefer to focus on the training and mentoring process, especially to enhance the skills, techniques and tactics of the team. There can be no doubt that such a coach has a close relationship with the players.

(d) Social consideration: As a normal human being, a coach does not miss his compassionate nature. Coaches like this will try to consider current conditions such as maturity level, skill level, health status and player environment before performing any planned activities.

(e) Social support: It is common for coaches to look at the welfare factors of a player and a team. Each player needs unwavering support from the coach on matters such as excellent interpersonal interaction, friendly service that gives them the freedom to set boundaries for the athlete to practice their daily life.

(f) Autocratic: Sometimes coaches have to take center stage by making their own decisions without giving players a chance to express themselves. Players rarely favor this style of leadership, but it should be applied in certain situations, especially when facing tough times during the game.

\subsection{Players' Motivation}

Motivation defined as the energy, the strength and the passion for the individual to do the thing he or she wants [20]. An individual who has a strong desire to do something without any force or direction is a person with a high level of motivation. According to [21], a highly motivated employee can increase job satisfaction, performance will improve, and productivity expected. In terms of football, players' motivations can be measured when they can train, follow the coach's instructions and play better in any given game [22].

In sports, average athlete motivation theory has something to do with Self-Determination Theory (SDT). According to [23], SDT focuses on the self-esteem of an individual that motivates them to perform a task on their own without the help of others. In short, SDT is a sharp guide for athletes to maintain their self-esteem and team performance to increase their motivation before, during and after a competition [24]. In these cases, there are six dimensions emphasized as proposed in SDT, namely intrinsic motivation, integrated motivation, identified motivation, introjected motivation, external motivation and amotivation [23].

Previously, several studies involving athlete motivation have been conducted around the world, including various sports [25],[26],[27]. In a study [25], it found that coaches with low self-esteem were able to enhance their players' motivations through positive feedback, supporting and creating a climate that most players liked. Meanwhile, a study [26] found that each athlete's motivations were different because of their focus and dreams of achieving their goals. Therefore, the role of the coach is critical to help each athlete realize that goal and to guide them so that they do not fall far short of success.

A recent study conducted by [27] found that athletes with high intrinsic motivation would perform whatever task the coach entrusted to them even in critical situations. However, this study focuses on gender factors in which female athletes have a higher motivation than men, so they often embrace the success of high intrinsic motivation. The findings of this study open a new chapter that an investigation should be conducted to find the influence of coach leadership style on players' motivation. This is because the findings of this study will provide different inputs by location and several different athletes leading to new contributions to the field of study [22].

\subsection{Research Framework}

According to the research, coach leadership style has six dimensions, namely democratic, positive feedback, training and instruction, social consideration, social support and autocratic. All of these dimensions are the result of a study [19] which presented a questionnaire on coach leadership, the Revised Leadership Scale for Sport (RLSS). Therefore, the study will examine six dimensions that influence players' motivation in football games involving adolescents. To facilitate understanding, this study was conducted under the following framework as Figure 1 below: 


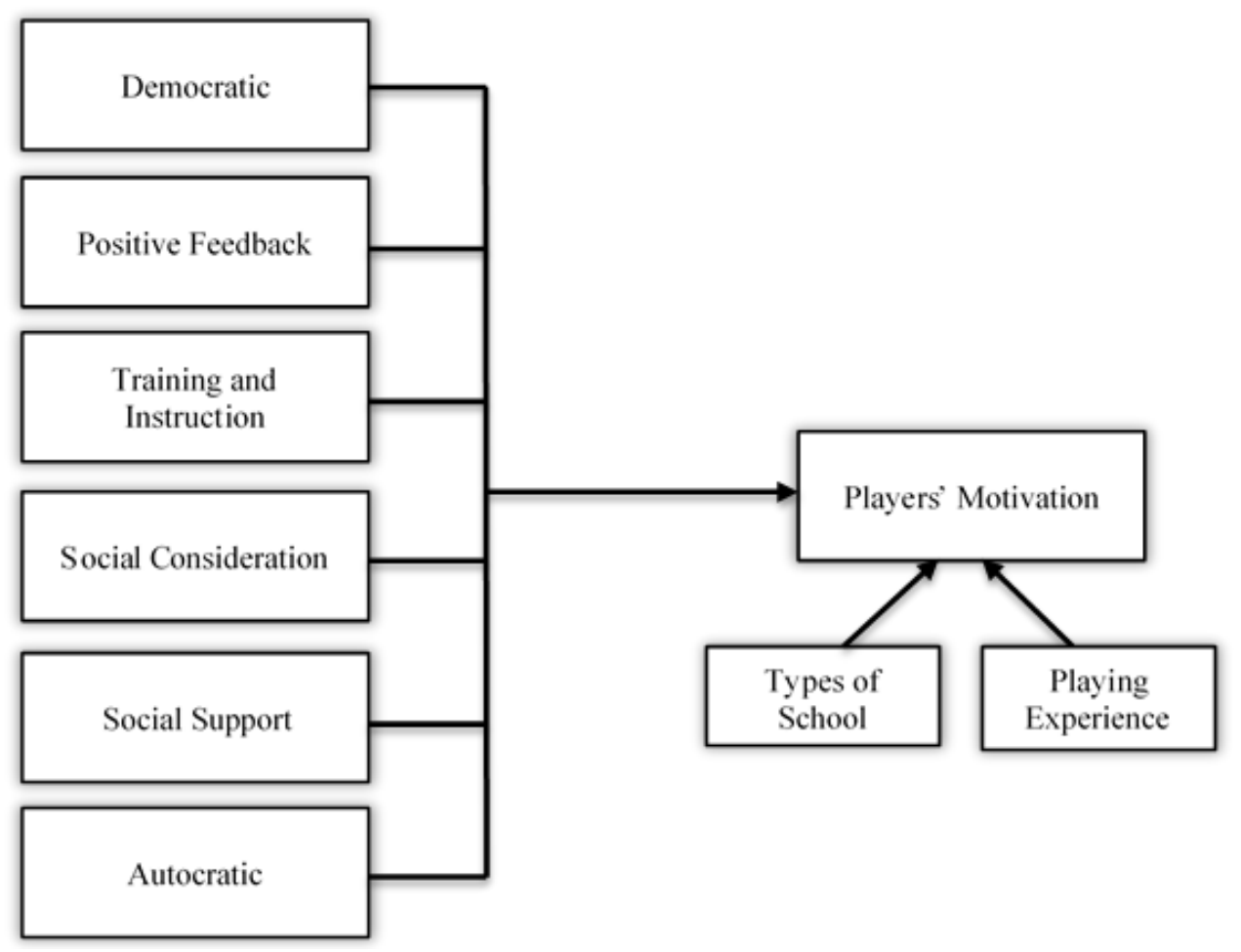

Figure 1. Research Framework

\section{Methodology}

This study uses a quantitative approach to examine the influence of coach leadership style on players' motivation involving sports schools in Malaysia. Generally, quantitative studies performed to collect data when involving prominent study locations and large respondents [28]. Therefore, a survey conducted to receive relevant information through the medium of questionnaire form. The survey method aims to obtain information about a phenomenon that occurs by describing the characteristics of a group of respondents at a particular time [29].

\subsection{Population and Sampling}

The population of this study is for athletes involved in football games at State Sports School (SSS) and also Malaysia Sports School (MSS). A total of 22 SSS and MSS schools exist throughout Malaysia, placing athletes in the age range of 13 to 19 years. All athletes in various sports fields are trained and trained intensively in sports, including academic accreditation by the Ministry of Education Malaysia (MOE) and the Ministry of Sport and Youth (MSY).

According to the current situation, the number of athletes in SSS and MSS is 6252. Of these, 550 athletes are footballers between the ages of 13 and 14 who are participating in MOE-sponsored under-14 tournaments. According to the table [30], the minimum number of respondents to take in was 234 players. To avoid problems such as missing questionnaires, inaccurate findings and incomplete forms, the respondents' size should be increased [31]. Therefore, a total of 313 players were selected as respondents in the study using a simple random sampling method.

\subsection{Instrumentation}

The instrument used to measure coach leadership style is the Revised Leadership Scale for Sport (RLSS) developed by [19]. The RLSS contains 60 items in total, covering six different dimensions. The dimensions are about the leadership styles practiced by the coach from the perspective of a young footballer. Previously, the RLSS has been widely used in studies involving coach leadership styles in various sports and has shown consistent values [9],[32],[33].

Besides, another variable was the players' motivation, which was adapted from the study [34]. The instrument called the Revised Sport Motivation Scale (SMS-II) divided into six dimensions, with a total of 18 questions in total. Previous studies using SMS-II have shown a high degree of reliability and suitability for use in different sports environments [34],[35]. The total number of items used for both instruments was 78 items.

The following Table 1 shows the breakdown of the number of items and the values of Cronbach's Alpha $(\alpha)$ by each dimension. These values were obtained after conducting the pilot study session. According to [29], a vital pilot study was conducted to test the logic, effectiveness and accuracy of the instrument before it distributed to real respondents. The results of the pilot 
study showed that all variables had an $\alpha$ value of greater than 0.70 . This value is sufficient to guarantee the validity and reliability of each item used as well as to build quality in the instrument [36].

Table 1. Reliability of Instruments

\begin{tabular}{|c|c|c|c|}
\hline Variables & Dimensions & Items & $\boldsymbol{\alpha}$ \\
\hline \multirow{4}{*}{ CLS } & Democratic & 12 & 0.82 \\
& Positive Feedback & 12 & 0.84 \\
& Training and Instruction & 10 & 0.78 \\
& Social Consideration & 10 & 0.75 \\
& Social Support & 8 & 0.84 \\
& Autocratic & 8 & 0.82 \\
& Overall & $\mathbf{6 0}$ & $\mathbf{0 . 8 8}$ \\
\hline \multirow{4}{*}{ PM } & Intrinsic Motivation & 3 & 0.80 \\
& Integrated Motivation & 3 & 0.77 \\
& Identified Motivation & 3 & 0.83 \\
& Introjected Motivation & 3 & 0.70 \\
& External Motivation & 3 & 0.92 \\
& Amotivation & 3 & 0.70 \\
& Overall & $\mathbf{1 8}$ & $\mathbf{0 . 9 3}$ \\
\hline
\end{tabular}

(Note: CLS - Coach Leadership Style; PM - Players' Motivation)

\subsection{Data Collection and Analysis}

In collecting research data, written consent must be made to the MOE. Only MOE can allow research to be conducted as this study involves students and organizations under their administration. Once the truth obtained, the questionnaire is distributed personally by the researcher. In this case, a meeting and explanation session were conducted with respondents in the selected schools. This method is appropriate so that respondents have a new understanding of the objectives of the study [37]. It is also able to avoid the confusion of the respondent when answering the question, and the researcher can interact with all the respondents.

Then, all collected data were analyzed using Statistical Package for the Social Sciences (SPSS) version 24.0 software. According to [29], SPSS is best used to describe research findings involving descriptive and inference analysis. Examples of descriptive statistics were used to describe respondents' background such as school type, age and football experience. Mean and standard deviation values were analyzed to identify the level of each variable. At the same time, inference examines such as Pearson's correlation test and multiple regression were also used to determine the relationship and influence of coach leadership style on players' motivation.

\section{Findings}

\subsection{Profile of the Respondents}

The respondents in this study were 313 players, of whom $263(84.0 \%)$ were players studying at State Sports School (SSS) and the remaining $50(16.0 \%)$ trained at
Malaysian Sports School (MSS). In terms of age, the average footballer is a 14-year-old student with 256 $(81.8 \%)$, while another $57(18.2 \%)$ is a 13 -year-old student. Besides, 213 players (68.1\%) had three years of football experience, followed by 69 players $(22.0 \%)$ with two years' experience, 19 players $(6.1 \%)$ had four years' experience, and nine players $(2.9 \%)$ has gained five years of experience. However, only three players $(1.0 \%)$ are recruits with one year of experience in the football field. The summary of the analysis based on the respondents' demographics shown in Table 2 below.

Table 2. Respondents by Types of School, Age, and Playing Experience

\begin{tabular}{|c|c|c|c|}
\hline Variables & Demographics & Frequencies & $\mathbf{\%}$ \\
\hline Types of & MSS & 50 & $16.0 \%$ \\
School & SSS & 263 & $84.0 \%$ \\
\hline \multirow{2}{*}{ Age } & 13 years old & 57 & $18.2 \%$ \\
& 14 years old & 256 & $81.8 \%$ \\
\hline \multirow{4}{*}{ Playing } & One year & 3 & $1.0 \%$ \\
Experience & Two years & 69 & $22.0 \%$ \\
& Three years & 213 & $68.1 \%$ \\
& Four years & 19 & $6.1 \%$ \\
& Five years & 9 & $2.9 \%$ \\
\hline
\end{tabular}

\subsection{The Level of Coach Leadership Style and Players' Motivation}

To assess the level of coach leadership style, mean values were used consisting of five sections, namely very high (4.21 - 5.00), high (3.41 - 4.20), medium (2.61 $3.40)$, low $(1.81-2.60)$ and very low $(0.00-1.80)$ [38]. These five categories are appropriate because the instruments used in this section are five-point scale. Based on the study, it was found that four dimensions coach leadership style showed high levels of positive feedback $(\mathrm{M}=3.80, \mathrm{SD}=0.71)$, training and instruction $(\mathrm{M}=3.98$, $\mathrm{SD}=0.68)$, social consideration $(\mathrm{M}=3.89, \mathrm{SD}=0.65)$, and social support $(\mathrm{M}=3.64, \mathrm{SD}=0.72)$. The other two dimensions were democratic $(\mathrm{M}=3.04, \mathrm{SD}=0.76)$ and autocratic $(\mathrm{M}=3.26, \mathrm{SD}=0.77)$ at the moderate level.

Overall, the level of coach leadership style variables was high, with a mean value of 3.60 , and the standard deviation was 0.48 . This finding proves that football coaches in sports schools across Malaysia have adopted high-style coach leadership to train Malaysian footballers under 14. The summary formulas for each dimension of coach leadership style shown in Table 3 below.

Table 3. The Level of Coach Leadership Style

\begin{tabular}{|c|c|c|c|}
\hline Dimensions & M & SD & Level \\
\hline Democratic & 3.04 & 0.76 & Medium \\
Positive Feedback & 3.80 & 0.71 & High \\
Training and Instruction & 3.98 & 0.68 & High \\
Social Consideration & 3.89 & 0.65 & High \\
Social Support & 3.64 & 0.72 & High \\
Autocratic & 3.26 & 0.77 & Medium \\
\hline Overall & $\mathbf{3 . 6 0}$ & $\mathbf{0 . 4 8}$ & High \\
\hline
\end{tabular}


Meanwhile, players' motivation level also measured in this study based on the mean values divided into seven sections namely very high (6.00 - 7.00), high (5.00 - 5.99), average high (4.00 - 4.99) medium (3.00 - 3.99), low (2.00 - 2.99) and very low $(1.00-1.99)$ [38]. It is appropriate since the instrument used to measure players' motivation is a seven-point scale. Based on the findings, it was found that the three dimensions of players' motivation showed high levels of intrinsic motivation $(\mathrm{M}=5.47, \mathrm{SD}=1.29)$, integrated motivation $(\mathrm{M}=5.29, \mathrm{SD}=1.30)$, and identified motivation $(\mathrm{M}=5.46, \mathrm{SD}=1.31)$. The findings also show that two dimensions of players' motivation are at the medium level of introjected motivation $(\mathrm{M}=4.91$, $\mathrm{SD}=1.38)$ and amotivation $(\mathrm{M}=4.58, \mathrm{SD}=1.75)$.

However, there is a single dimension in players' motivation, which is the external motivation $(\mathrm{M}=3.71$, $\mathrm{SD}=1.76$ ) of moderate level. When computed, the level of overall players' motivation was medium quality with a mean value of 4.90 and the standard deviation was 0.83 . The results show that football players under 14 in sports schools across Malaysia have an only moderate level of motivation. For more details, a summary of each player's motivation dimensions is presented, as shown in Table 4.

Table 4. The Level of Players' Motivation

\begin{tabular}{|c|c|c|c|}
\hline Dimensions & M & SD & Level \\
\hline Intrinsic Motivation & 5.47 & 1.29 & High \\
Integrated Motivation & 5.29 & 1.30 & High \\
Identified Motivation & 5.46 & 1.31 & High \\
Introjected Motivation & 4.91 & 1.38 & Medium High \\
External Motivation & 3.71 & 1.76 & Medium \\
Amotivation & 4.58 & 1.75 & Medium High \\
\hline Overall & $\mathbf{4 . 9 0}$ & $\mathbf{0 . 8 3}$ & Medium High \\
\hline
\end{tabular}

\subsection{Differences in Players' Motivation Based on Types of School and Playing Experience}

Referring to Levene's Test for Equality of Variance in the t-test, it found that the $\mathrm{p}$-value was not significant $(\mathrm{F}=$ $0.85, p=0.36$ ), which was $p>0.05$. This case proves that there are two types of schools that are homogeneous and that the variance values are obeyed. Based on Table 5, it found that there was a significant difference between players' motivation based on the types of school factor where $\mathrm{t}(311)=3.138, \mathrm{p}<0.01$. This result means that the motivation of the footballers under 14 at the Malaysia Sports School (MSS) and the State Sports School (SSS) is different. The motivation for football players in the MSS was significantly higher $(\mathrm{M}=5.24, \mathrm{SD}=0.78)$ than for the players in the SSS $(\mathrm{M}=4.84, \mathrm{SD}=0.83)$.

Table 5. A T-Test Analysis of Players' Motivation by Types of School

\begin{tabular}{|c|c|c|c|c|c|}
\hline $\begin{array}{c}\text { Types of } \\
\text { School }\end{array}$ & $\mathbf{M}$ & SD & $\mathbf{F}$ & t-value & df \\
\hline MSS & 5.24 & 0.78 & 0.85 & $3.138^{* *}$ & 311 \\
SSS & 4.84 & 0.83 & & & \\
\hline
\end{tabular}

$* * \mathrm{p}>0.05$
On the other hand, ANOVA tests showed no significant difference in players' motivation based on the playing experience factor, with $F$ values $(4,308)=2.25, p>0.05$. In other words, the motivation of the under 14 football players in sports schools across Malaysia is no different in terms of playing experience. Nevertheless, Levene's Test for Equality of Variance showed no significant value ( $\mathrm{F}=$ $0.64, p>0.05$ ), which means that the variation of the groups playing experience is homogeneous and suggests that variance values observed.

According to Table 6, the mean value of the playing experience was approximately equal to 3 years playing experience $(\mathrm{M}=4.93, \mathrm{SD}=0.84), 2$ years playing experience $(\mathrm{M}=4.92, \mathrm{SD}=0.85)$ and 5 years playing experience $(\mathrm{M}=4.90, \mathrm{SD}=0.70)$. However, there were only slightly lower mean differences from the previous group of 4 years playing experience $(\mathrm{M}=4.74, \mathrm{SD}=0.65)$ and 1 year playing experience $(\mathrm{M}=3.54, \mathrm{SD}=0.77)$.

Table 6. An ANOVA Analysis of Players' Motivation by Playing Experience

\begin{tabular}{|c|c|c|c|c|c|}
\hline $\begin{array}{c}\text { Playing } \\
\text { Experience }\end{array}$ & M & SD & df & F & p \\
\hline 1 year & 3.54 & 0.77 & 4,308 & 2.25 & 0.06 \\
2 years & 4.92 & 0.85 & & & \\
3 years & 4.93 & 0.84 & & & \\
4 years & 4.74 & 0.65 & & & \\
5 years & 4.90 & 0.70 & & & \\
\hline
\end{tabular}

\subsection{Relationship between Coach Leadership Styles and Players' Motivation}

The results of the study, as shown in Table 7, show that there is a moderate positive relationship [38] between coach leadership style and players' motivation. This is clearly explained in the Pearson correlation coefficient (r), where both variables accounted for $r=0.488, p=0.000(p$ $<0.01$ ). This fact indicates that the motivation of the 14 football players in sports schools across Malaysia is only modestly related to the manner or style of their coaches implementing instruction or coaching. Although the relationship is simple, it is still important to prove the existence of a coach in improving each player's motivation.

Table 7. Correlation Analysis between Coach Leadership Style and Players' Motivation

\begin{tabular}{|c|c|c|c|}
\hline Variables & & CLS & PM \\
\hline \multirow{2}{*}{ CLS } & Pearson's Correlation & 1 & $0.488^{* *}$ \\
& Sig. (2-tailed) & & 0.00 \\
& Pearson's Correlation & $0.488^{* *}$ & 1 \\
PM & Sig. (2-tailed) & 0.00 & \\
\hline
\end{tabular}

(Note: CLS - Coach Leadership; PM - Players' Motivation)

Out of the six dimensions of coach leadership style, only five dimensions showed significant relationship with players 'motivation as shown in Table 8. Four dimensions showed a significant and modest positive relationship with 
players' motivation which was positive feedback $(\mathrm{r}=$ $0.425, \mathrm{p}<0.01)$, training and instruction $(\mathrm{r}=0.499, \mathrm{p}<$ $0.01)$, social consideration $(\mathrm{r}=0.545, \mathrm{p}<0.01)$, and social support $(r=0.462, p<0.01)$. Another dimension of democratic $(r=0.137, p<0.05)$ had a significant positive and poor relationship with players' motivation.

However, there is one dimension that has no significant negative relationship with players' motivation which is autocratic $(\mathrm{r}=-0.067, \mathrm{p}>0.05)$. The situation also suggests that coaches who practice autocratic leadership styles are less comfortable with football players under 14 in sports schools across Malaysia. However, the practice of other coaches' leadership styles shines that the method is favorable and enhances player motivation. Table 8 below shows the correlation formulas between dimensions in coach leadership style and players' motivation.

Table 8. Correlation Analysis Based on Dimensions of Coach Leadership Style and Players' Motivation

\begin{tabular}{|c|c|c|}
\hline & Dimensions & Players' Motivation \\
\hline \multirow{7}{*}{ Pearson's } & Democratic & $0.137^{*}$ \\
& Sig. (2-tailed) & 0.02 \\
& N & 313 \\
& Positive Feedback & $0.425^{* *}$ \\
& Sig. (2-tailed) & 0.00 \\
& N & 313 \\
& Training and Instruction & $0.499^{* *}$ \\
& Sig. (2-tailed) & 0.00 \\
& N & 313 \\
& Social Consideration & $0.545^{* *}$ \\
& Sig. (2-tailed) & 0.00 \\
& N & 313 \\
& Social Support & $0.462^{* *}$ \\
& Sig. (2-tailed) & 0.00 \\
& N & 313 \\
& Autocratic & -0.067 \\
& Sig. (2-tailed) & 0.24 \\
& N & 313 \\
\hline
\end{tabular}

*Correlation is significant at the 0.05 level (2-tailed)

**Correlation is significant at the level 0.01 (2-tailed)

\subsection{The Effect of Coach Leadership Style on Players' Motivation}

Table 9 shows one study result generated by multiple linear regression analysis. This test conducted to identify which dimensions of coach leadership style affect players' motivation. Based on the adjusted $\mathrm{R}^{2}$ value of 0.317 , it shows that there is a $31.7 \%$ contribution given by the dimensions of coach leadership style to players' motivation. The input is not enormous, but it has a considerable impact on improving the motivation of football players in sports schools. Referring to the value of $\mathrm{F}=25.109$ in the ANOVA analysis, it found that there was a significant difference in each dimension of coach leadership style over players' motivation (sig. $=0.00 \mathrm{p}$ $<0.05$ ).
Table 9. Multiple Linear Regression Analysis Coach Leadership Style on Players' Motivation

\begin{tabular}{|c|c|c|c|}
\hline Dimensions & Beta & t & Sig \\
\hline (constant) & & 6.959 & 0.000 \\
Democratic & -0.115 & -1.995 & 0.047 \\
Positive Feedback & 0.102 & 1.376 & 0.170 \\
Training and Instruction & 0.135 & 1.597 & 0.111 \\
Social Consideration & 0.307 & 3.414 & 0.001 \\
Social Support & 0.137 & 1.829 & 0.068 \\
Autocratic $^{2}$ value & -0.074 & -1.468 & 0.143 \\
\hline Adjusted R $^{2}$ value & & & 0.330 \\
F Value $_{\text {Sig. }}$ & & 0.317 \\
& & & 25.109 \\
\end{tabular}

According to Table 9, the findings also show that there are two dimensions of coach leadership style that contribute significantly to players' motivation. These dimensions were democratic $(\beta=-0.115, \mathrm{p}<0.05)$ and social consideration $(\beta=0.307, \mathrm{p}<0.05)$. However, the other four dimensions showed insignificant effects $(p>$ $0.05)$ where positive feedback $(\beta=0.102, \mathrm{p}>0.05)$, training and instruction $(\beta=0.135, \mathrm{p}>0.05)$, social support $(\beta=0.137, p>0.05)$ and autocratic $(\beta=-0.074, p>$ $0.05)$. Thus, the dimensions of coach leadership style accounted for $31.7 \%$ of the revenue from the adjusted $\mathrm{R}^{2}$ value of 0.317 .

\section{Discussions}

The use of RLSS instruments [19] and SMS-II [34] in this study is undoubtedly an exciting finding after the survey conducted on the respondents' aspect of Malaysia. Noteworthy, the respondents of the study were among the football players under the age of 14 who are trained in sports schools throughout Malaysia. This phenomenon makes these players closest to the coach and has a deep understanding of their coach's personality and behaviours.

As expected, the level of coach leadership style in sports schools across Malaysia is high. This case is due to the growing sense of respect among young players who feel that coaches are individuals who need to be followed closely [6],[39]. According to [40], a coach is an influential individual in a team until he or she determines the direction and fall or the rise of a team. This finding is also supported by [33], where coaches are fair, transparent in guiding their players, and tolerant in their characters. Therefore, a well-respected coach will surely have the characteristics of each player under his guidance.

Meanwhile, the findings for the players' motivation level showed inconsistent results. However, the dimensions of intrinsic motivation, integrated motivation and identified motivation are high. For example, [41] stated that athletes with intrinsic motivation would do a great job or training because of their deep interest in the role. Of course, the motivation dimension is indicative of a high-quality level as most footballers are very excited to be able to train with friends and participate in organized 
games [42]. This excitement exacerbated when coaches are continually giving encouragement, competent guidance, and lowering their egos to understand the needs of players over time [26].

Besides, the findings show that players who practice in MSS have higher mean levels than players in SSS. As you know, choosing to MSS is more complicated than SSS because it has to go through the phases of selection. Of course, players of high caliber, good potential and high skill will be the go-to point for selected training centers [11]. When chosen for the MSS, it is clear that young players will try their hardest, showcase their talents and persuade their coaches to be selected as the top team in any big tournament [18],[43].

Playing experience is not a vital determinant of an athlete's success today. With state-of-the-art training facilities, footballers are more likely to follow a more intensive training process and be guided by experienced coaches [22]. According to the study [7], the willingness of the players to undergo training, follow the procedure well and diligently focus on the weaknesses that will cause their performance to rise higher. Thus, an athlete's performance not confined to experience, but factors such as motivation, well-being and high goals make them more motivated to succeed in a single match [15].

Meanwhile, studies show that there is a simple correlation between coach leadership style and players' motivation. In a study [25] stated that the motivation of each player varies based on the behavior taken by a coach. A coach who has a high ego is assertive, does not care about the well-being of a player and is less likely to drop a player's motivation during training or competition. At a young age, players need constant support, guidance and encouragement to improve their self-esteem, confidence and motivation so that their performance is at their peak [13],[14].

It is alarming to see that only $31.7 \%$ of the dimensions in the coach leadership style contribute to players' motivation. This contribution made up of only two significant aspects of democratic and social consideration. Yes, it is sure that when coaches have democratic behavior, they will try to reach out to players with low egoism, ask for players' views and discuss possible improvements in the future [7],[32]. Clearly, [39] states that democracy can also be practiced by enhancing good relations with players in addition to effective communication methods.

Another dimension that contributes to players' motivation is social consideration. As previously explained, coaches are rational human beings and have high humanities [16], [42]. This behavior gives a lot of pleasure to young footballers, especially those who are far from family. Loving, parenting, caring, aware of health issues and personal issues are the most praiseworthy behaviors that every coach should have [27]. It makes football players more motivated when they know they are not only well cared for but loved.

\section{Conclusions}

Football is not only an entertaining game, but it is a sport held based on unity. Football performances will not entertain if the players do not show the expected quality of the game. In other words, the game of football will look boring if the quality of the match watched by the players is too low. In this regard, coaches have a crucial role to play in thinking strategies to improve the quality of the game. Coaches should think of ways to increase the motivation of the players either before, during, or after the game [10].

Great coaches will always try to give full attention and focus to the team. From the team administration process to the performance of the players on the field, coaches need a high level of determination and commitment to form a strong team. Therefore, the coach must have an appropriate leadership style to train, provide guidance, and increase the motivation of the players so that the goal of victory in each match will achieve [43]. This spirit of leadership is needed so that it can produce something positive in a team.

In MSS and SSS, the players are lucky because they have been selected and placed in one location with intensive guidance in the sport of football. Experienced coaches have mandated to practice the concept of coach leadership style in every instruction, rule, and training to form players among students at a very young age. At the age of 14, this group needs to be formed, nurtured, given proper guidance so that the potential and talent available can be polished and shine one day. Therefore, among the crucial factors that need to emphasize is their motivation to face any tournament. Through the concept of structured training, proper time management, and nutrition according to the given pyramid system, this group of teenage players can stand out, even be able to shine to a higher stage.

As you know, this study has supported several previous studies in the field of coach leadership styles such as studies by [11], [32], and [39]. For example, the study of [11] argues that the motivation of players will increase if they get guidance from coaches who practice coach leadership style properly. This finding is also supported by [32] and [43] that coach leadership style is not only able to increase player motivation, but it can have an impact on player satisfaction and improve good relations between players and coaches.

\section{Acknowledgements}

This article was conducted as part of a doctoral study by the first author and the second author at Universiti Utara Malaysia. This authors is fully sponsored by the 
Ministry of Education Malaysia (MOE), under the Federal Training Gift Program (HLP) for recruitment in 2018.

\section{REFERENCES}

[1] FIFA, "Coca-cola world men's ranking", Retrieved from https://www.fifa.com/fifa-world-ranking, 2020.

[2] Y. Cho, Football in Asia: History, culture and business, Oxon, UK: Taylor \& Francis, 2015.

[3] M. Amara, "Football in West Asia", In J. Hughson, K. Moore, R. Spaaij, \& J. Maguire (Eds.), Handbook of football studies, Oxon, UK: Taylor \& Francis, 2017.

[4] J. Rosly, "MOM cadang bida Sukan Asia 2030", Berita Harian. Retrieved from https://www.bharian.com.my, 2019.

[5] G. Carroll, Talent identification in football: an exploratory study from the scouts perspective, Undergraduate thesis, University of Chichester, 2019.

[6] T. Webb, M Dicks, D. J. Brown, and J. O'Gorman, “An exploration of young professional football players' perceptions of the talent development process in England", Sport Management Review, 2019, pp. 1-12.

[7] N. Mohd Noor, Hubungan tingkah laku kejurulatihan dengan motivasi atlet bola sepak di sekolah sukan Malaysia, Master thesis, Universiti Putra Malaysia, 2014.

[8] M. Hasan, A. K. Singh, and J. Singh, "Achievement motivation of Indian field hockey players at three different levels of competitions", Journal of Physical Education Research, vol. 2(1), 2015, pp. 71-81.

[9] A. Mohd Pilus, N. Muhamad, and H. Hussin, "The correlation between coaching style and smartphone usage on students satisfaction", Journal of Engineering and Applied Sciences, vol. 14(1), 2019, pp. 1695-1698.

[10] G. Dyakova, T. Dyakov, and L. Angelova, "Study of the students' interest in the football game, motivation and desire for practicing football", Trakia Journal of Science, vol. 15(Suppl.1), 2017, pp. 375-382.

[11] J. K. Govindan, K. G. Soh, Y. Aminuddin, and M. S. Omar Fauzee, "Persepsi atlet terhadap gaya tingkah laku kepimpinan jurulatih bola sepak sekolah yang digemari dengan gaya tingkah laku kepimpinan sebenar jurulatih bola sepak di daerah Alor Gajah, Melaka", Malaysian Journal of Movement, Health \& Exercise, vol. 8(1), 2019, pp. 123-133.

[12] A. Din, S. Abd Rashid, and M. I. Awang, "Aspek pengurusan program latihan dan kesannya terhadap kepuasan atlet sekolah sukan", International Journal of Management Studies, vol. 22(1), 2015, pp. 73-95.

[13] W. A. S. S. Lee, and S. A. Rengasamy, "Gaya Kepimpinan Jurulatih Yang Diminati Atlet-Atlet Sekolah Menengah Di Malaysia Berasaskan Jantina", Jurnal Kepimpinan Pendidikan, vol. 3(1), 2015, pp. 32-46.

[14] K. Mouloud, and B. A. Elkader, "Self-efficacy and Achievement Motivation among Football Player", The Swedish Journal of Scientific Research, vol. 3(11), 2016, pp.
$13-19$.

[15] M. A. Y. Lescroart, M. E. Brown, and T.S. Paskus, "The relationship between ethical and abusive coaching behaviors and student-athlete well-being", Sport, Exercise, and Performance Psychology, vol. 4(1), 2015, pp. 36-49.

[16] P. Chelladurai, "Leadership in sport organizations", Canadian Journal of Applied Sport Sciences, vol. 5, 1980, pp. 226-231.

[17] R. H. Cox, Sport psychology: Concepts and applications (6th ed.), Boston: McGraw-Hill, 2007.

[18] K. S Avci, F. Cepikkurt, and E. K. Kale, "Examination of the relationship between coach-athlete climate for volleyball players", Universal Journal of Educational Research, vol. 6(2), 2018, pp. 346-353.

[19] J. Zhang, B. E. Jensen, and B. L. Mann, "Modification and revision of the Leadership Scale for Sport", Journal of Sport Behavior, vol. 20(1), 1997, pp. 105-122.

[20] S. P. Robbins, Organizational Behavior: Concepts, controversies and application (11th ed.) New Jersey: Prentice Hall, 2005.

[21] H. Alina, and M. Liliana, "Research concerning the motivation's qualification for performance athletes", Journal of Physical Education and Sport, vol. 27(2), 2010, pp. 88-95.

[22] S. Toktas, and M. Bas, "Investigation of the relationship between the self-confidence and motivation of high school students participating school sport contests", Universal Journal of Educational Research, vol. 7(2), 2019, pp. 472479.

[23] E. L. Deci, and R. M. Ryan, "The what and why of goal pursuits: Human needs and self-determination of behavior", Psychology Inquiry, vol. 11(1), 2000, pp. 227-268.

[24] M. Standage, and R. M. Ryan, "Self-determination theory and exercise motivation: facilitating self-regulatory processes to support and maintain health and well-being", In G. C. Roberts \& D. C. Tresure (Eds.), Advances in Motivation in sport and exercise (3rd ed.), Champaign, IL: Human Kinetics, 2012.

[25] R. Baric, and V. Bucik, "Motivational differences in athletes trained by coaches of different motivational and leadership profiles", Journal Kinesiology, vol. 41(2), 2009, pp. 181194

[26] M. Goose, and S. Winter, "The coach's impact on long distance runners' training and competition motivation", International Journal of Sports Science and Coaching, vol. 7(2), 2012, pp. 383-398.

[27] H. F. Kucukibis, and M. Gul, "Study on sports high school students' motivation levels in sports by some variables", Universal Journal of Educational Research, vol. 7(3), 2019, pp. 839-847.

[28] L. Cohen, L. Manion, and K. Morrison, Research Methods In Education (8th ed.), New York, NY: Routledge, 2018.

[29] F. Hussin, J. Ali, and M. S. Z. Noor, Kaedah penyelidikan \& analisis data SPSS, UUM Sintok, Kedah: UUM Press, 2014.

[30] R. V Krejcie, and D. W. Morgan, "Determining sample size 
for research activities", Educational and Psychological Measurement, vol. 38(1), 1970, pp. 607-610.

[31] M. N. Omar, S. N. Ismail, and A. L. Kasim, "Karakter kepimpinan teknologi pengetua dalam pengintegrasian ICT di sekolah menengah", JuPiDi: Jurnal Kepimpinan Pendidikan, vol 7(1), 2020, pp. 28-46.

[32] M. N. Nazarudin, M. S. Omar Fauzee, M. Jamalis, K. G. Soh, and Din, "Coaching leadership styles and athlete satisfaction among Malaysian University basketball team", Research Journal of International Studies, vol. 9, 2009, pp. 4-11.

[33] J. Sullivan, and M. Dhurup, "The relation of coaching context and coach education to coaching efficacy and perceived leadership behaviors in youth sport", Sport Psychologist, vol. 26(1), 2012, pp. 122-130

[34] L. G. Pelletier, M. A. Rocchi, R. J. Vallerand, E. L. Deci, and R. M. Ryan, "Validation of the revised sport motivation scale (SMS-II)", Psychology of Sport and Exercise, vol. 14(3), 2013, pp. 329-341.

[35] J. Schaefer, S. A. Vella, M. S Allen, and C. A. Magee, "Competition anxiety, motivation, and mental toughness in golf', Journal of Applied Sport Psychology, vol. 21(10), 2016, pp. 1475-1483.

[36] J. J. F. Hair, W. C. Black, , B. J. Babin, and R. Anderson, Multivariate data analysis (7th ed.), Essex: Pearson Education Limited, 2014.

[37] Y. P. Chua, Kaedah dan statistik penyelidikan (Buku 2):
Asas statistik penyelidikan (2nd ed.), Kuala Lumpur: McGraw-Hill Education, 2012.

[38] G. Darusalam, and S. Hussin, Metodologi penyelidikan dalam pendidikan: Amalan dan analisis kajian (2nd ed.) Kuala Lumpur: Penerbitan Universiti Malaya, 2018.

[39] G. Borghi, P. H. Borges, V. M. Menegassi, and G. S. W. Rinaldi, "Relationship between preferred leadership style and motivation in young soccer regional players", Journal of Physical Education and Sport, vol. 17(4), 2017, pp. 25992603.

[40] L. Keatlholetswe, and L. Malete, "Coaching Efficacy, Player Perceptions of Coaches' Leadership Styles, and Team Performance in Premier League Soccer", Research Quarterly for Exercise and Sport, 2019, pp. 1-9.

[41] R. M. Ryan, and E. L. Deci, “Active human nature”, In M. S. Hagger \& N. L. Chatzisarantis (Eds.), Intrinsic motivation and self-determination in exercise and sport, pp. 1-19, Champaign, IL: Human Kinetics, 2007.

[42] H. P. N. Perera, "Does the coach leadership behavior mediates the influence of factors acffecting coach leadership behavioral styles on team succes", International Journal of Human Movement and Sports Sciences, vol. 7(3), 2019, pp. 51-57.

[43] S. Samur, "Organization design in football management process", International Journal of Human Movement and Sports Sciences, vol. 6(2), 2018, pp. 38-46. 